\title{
Trade-Based Manipulation Or Speculative Bubble: A Case Study
}

Xiaofeng Zhao, Southern Arkansas University, USA

\begin{abstract}
This paper examines the unusual and puzzling stock price performance of USEC Inc. during July 2013. The stock price surged as much as ten times during merely sixteen trading days without apparent value-changing information being released. Four possible reasons are analyzed - mean reversion, information-based manipulation, speculative bubble, and trade-based manipulation. Trade-based manipulation and speculative bubble resulting from investors' overconfidence seem to be more plausible and better explain the dramatic stock price changes.
\end{abstract}

Keywords: Pump-and-Dump; Manipulation; Speculative Bubble

\section{INTRODUCTION}

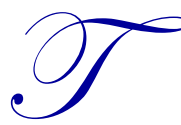

he security markets often see some stocks with prices increasing quickly followed by a slow decline. Many times little significant news is released or business changes are made during the process. When the stock price surges, trading volume and price volatility usually increase significantly, which happens mostly for mini- or small-cap stocks and during the stock market boom, and it is often viewed as a "pumpand-dump" scheme. USEC Inc. stock price during July 2013 provides a good example. After the reverse stock split, its stock price declined from the post-reverse-split price of $\$ 7.33 /$ share on July 1, 2013, to $\$ 2.96 /$ share on July 8, 2013 , with the low reaching $\$ 2.60 /$ share during the day. Since then, the stock price climbed back up and skyrocketed monotonically all the way to close to $\$ 29.02$ on July 29,2013 . It took merely sixteen trading days for the stock to increase a stunning 10 times. The trading volume also greatly increased to almost 1.3 million shares per day in July compared to average daily volume of only 18,097 shares in the previous month and 32,846 shares in the preceding 52 weeks. The stock then slowly declined in the following three months and dropped to about $\$ 6$ by early November. Figure 1 shows the stock price movement between July 2013 and November 2013.

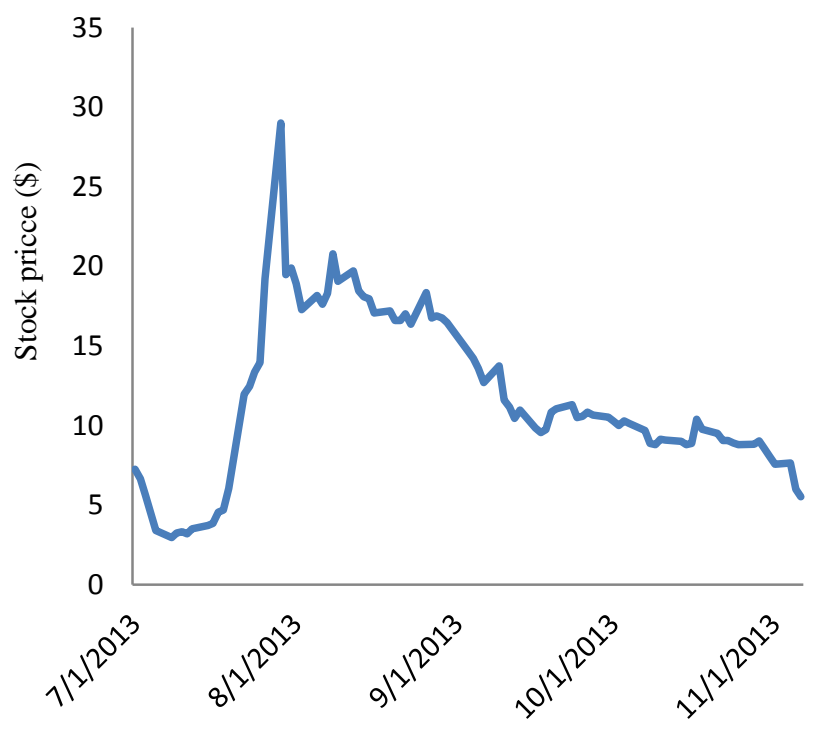

Figure 1: USEC Inc. Stock Price Movement 
Given the fact that the stock decreased to its pre-reverse-split price level or even lower, apparently it was inflated and could not stay at the high level. The stock price surge in July 2013 did not look like a result of mean reversion or value correction as identified by Fama and French (1988) and Poterba and Summers (1988). The stock had been declining consistently since Japan's Fukushima Daiichi accident and the subsequent shut-down of most Japanese nuclear power plants and negative sentiment to nuclear energy worldwide. The deteriorating financial numbers in the last three years are consistent with and justified the plummeting stock price. During the stock price surge, no compelling evidence was found showing that the uranium market would be dramatically improving and the company's business getting significantly better. In other words, the business fundamentals did not support such a huge stock value change in July 2013. In addition, the stock prices of its publicly-traded competitors in the uranium sector were changed only marginally or remained unchanged during the same period. Therefore, mean reversion as an explanation of the dramatic price surge can be ruled out.

During the period of the stock price increase, there was little significant news released which could dramatically change the stock value. On July 29th, USEC Inc. updated its American centrifuge research, development, and demonstration program and indicated that the program was on both budget and schedule, with five of the nine milestones certified by the Department of Energy. Another piece of news that could potentially affect the whole uranium industry was the election of pro-nuclear Prime Minister Shinzo Abe on July 21, 2013. The USEC Inc. stock more than tripled after the Japanese election. It seems that overly optimistic investors speculated that the election of a new pro-nuclear Prime Minister would change Japanese nuclear policy and reopen nuclear power plants. This could relieve the glut of uranium supply, lift the price of uranium, and improve the firm's financial situation. On the other hand, pessimistic investors were kept out of the market due to short-sale constraints. As many researchers (Miller, 1977; Harrison \& Kreps, 1978; Jarrow, 1981; Chen, Hong, \& Stein, 2002; Scheinkman \& Xiong, 2003; Ofek \& Richardson, 2003; Hong, Scheinkman, \& Xiong, 2006) demonstrate, the combined effect of heterogeneous beliefs and short-sale constraints create speculative bubbles, as in the case of the Internet Bubble (Ofek \& Richardson, 2003).

\section{BACKGROUND}

USEC Inc. is a global energy company engaged in the supply of low enriched uranium (LEU) for commercial nuclear power plants in the United States, Japan, and internationally. The company was created as a government corporation in order to restructure the government's uranium enrichment operation and was privatized on July 28, 1998. Since then, the company's stock has been trading on New York Stock Exchange (NYSE) under the ticker symbol USU. Hereafter, USU and USEC Inc. will be used interchangeably.

Since Japan's Fukushima Daiichi accident, occurring as a result of the March 11, 2011 earthquake and subsequent tsunami, USU stock consistently declined from about $\$ 6 /$ share $(\$ 150 /$ share after adjusting reverse stock split, which will be discussed below) in early 2011 to below $\$ 1$ ( $\$ 25 /$ share after adjusting reverse stock split) in mid2012 and continued to drop and trade under \$1/share. On May 24, 2012, USEC Inc. received a continued listing standards notice from the New York Stock Exchange. The NYSE requires the average closing price of a listed company's common stock to be at least $\$ 1.00$ per share over a consecutive 30 trading-day period. To regain compliance with the NYSE continued listing requirement regarding $\$ 1.00$ minimum share price, the company announced 1-for-25 reverse stock split effective on July 1, 2013. When the stock market opened on July 2, 2013, USEC's common stock began trading on a split-adjusted basis.

Since the reverse stock split, USEC Inc. common stock started its stunning movement. It initially plummeted from the split-adjusted closing price of \$7.33/share on July 1, 2013 to $\$ 2.96 /$ share on July 8, 2013 with the lowest price reaching $\$ 2.60 /$ share on the same day. It took merely four trading days for the stock value to decline by $60 \%$, even though there was no news release from the company or new public information in the uranium industry except two commentary articles from Seeking Alpha ${ }^{1}$ - one in a positive tone and the other in a negative tone. During the next three weeks, the stock climbed back and soared all the way to close at $\$ 29.02 /$ share on July 29, 2013 with heavy trading. Table 1 lists stock prices and daily trading volumes. The stock increased by a

\footnotetext{
${ }^{1}$ Seeking Alpha is a platform for investment research with over 7,000 contributing authors and 20,000 commenters. They cover over 3,000 small and mid-cap stocks. Their articles frequently move stocks.
} 
whopping $880 \%$ during the fifteen trading days, and the average daily return during this period is $18.7 \%$. The average daily trading volume was $1,277,617$ shares during July compared to only 18,097 in the previous month and 32,846 during the previous 52 weeks. During the same period, the S\&P 500 index increased by $2.74 \%$ and the stocks of its publicly-traded competitors changed by $23.2 \%, 1.6 \%, 22.7 \%, 10.1 \%$, and $-4.1 \%$ for URRE, URZ, URG, DNN, and CCJ, respectively.

Table 1: Stock Price Movement and Trading Volume during July 2013 for USEC, Inc and Its Publicly-Traded Competitors

\begin{tabular}{|c|c|c|c|c|c|c|c|c|c|c|c|c|c|c|}
\hline \multirow{2}{*}{ Date } & \multirow[b]{2}{*}{ Close } & \multirow[b]{2}{*}{ Volume } & \multicolumn{2}{|c|}{ URRE } & \multicolumn{2}{|c|}{ URZ } & \multicolumn{2}{|r|}{ URG } & \multicolumn{2}{|c|}{ UEC } & \multicolumn{2}{|c|}{ DNN } & \multicolumn{2}{|c|}{$\mathrm{CCJ}$} \\
\hline & & & Close & Volume & Close & Volume & Close & Volume & Close & Volume & Close & Volume & Close & Volume \\
\hline July 31, 2013 & 19.90 & $2,550,630$ & 3.76 & $2,232,099$ & 1.49 & 698,604 & 1.17 & $1,029,043$ & 2.31 & 972,773 & 1.27 & 825,939 & 20.32 & $1,191,702$ \\
\hline July 30, 2013 & 19.48 & $3,069,666$ & 4.50 & $3,056,490$ & 1.50 & 998,510 & 1.25 & 799,635 & 2.35 & $1,033,803$ & 1.32 & 954,418 & 20.74 & $1,222,627$ \\
\hline July 29, 2013 & 29.02 & $3,835,433$ & 5.32 & $8,470,139$ & 1.54 & $3,461,983$ & 1.31 & $1,196,008$ & 2.49 & $1,694,816$ & 1.31 & $1,824,162$ & 20.59 & $1,525,703$ \\
\hline July 26, 2013 & 19.21 & $3,868,232$ & 4.15 & $2,863,343$ & 1.43 & $1,855,976$ & 1.30 & 741,055 & 2.49 & $1,199,662$ & 1.34 & $1,626,848$ & 21.32 & $1,589,190$ \\
\hline July 25,2013 & 13.97 & $1,221,468$ & 3.08 & 383,492 & 1.35 & 435,567 & 1.28 & 491,986 & 2.38 & 411,473 & 1.32 & $1,019,524$ & 21.24 & 691,754 \\
\hline July 24,2013 & 13.35 & $1,786,588$ & 3.40 & 644,427 & 1.35 & 488,335 & 1.27 & 347,081 & 2.35 & 937,054 & 1.33 & $2,048,135$ & 21.09 & 880,762 \\
\hline July 23, 2013 & 12.46 & $3,105,006$ & 3.35 & $2,006,901$ & 1.30 & $1,521,594$ & 1.31 & 890,683 & 2.52 & $1,635,329$ & 1.30 & $1,857,480$ & 21.22 & $2,593,897$ \\
\hline July 22, 2013 & 11.98 & $3,881,502$ & 3.20 & $1,313,848$ & 1.42 & $1,444,678$ & 1.34 & $1,381,113$ & 2.46 & $1,372,482$ & 1.32 & $4,408,264$ & 21.98 & $2,192,000$ \\
\hline July 19,2013 & 6.05 & 570,128 & 2.60 & 47,212 & 1.17 & 166,579 & 1.17 & 569,447 & 2.19 & 287,736 & 1.25 & 622,488 & 21.23 & 984,943 \\
\hline July 18, 2013 & 4.68 & 307,681 & 2.50 & 30,074 & 1.18 & 164,943 & 1.08 & 590,289 & 2.21 & 370,418 & 1.23 & 637,218 & 21.29 & 799,915 \\
\hline July 17, 2013 & 4.56 & 390,059 & 2.48 & 55,407 & 1.14 & 170,704 & 1.11 & 237,497 & 2.21 & 306,598 & 1.22 & 597,954 & 20.99 & $1,397,720$ \\
\hline July 16, 2013 & 3.84 & 77,952 & 2.52 & 35,144 & 1.14 & 151,082 & 1.12 & 346,467 & 2.19 & 446,112 & 1.27 & 716,863 & 20.97 & $1,702,627$ \\
\hline July 15,2013 & 3.73 & 187,263 & 2.56 & 14,920 & 1.15 & 186,488 & 1.17 & 482,294 & 2.17 & 660,454 & 1.20 & 488,674 & 21.35 & $1,439,293$ \\
\hline July 12,2013 & 3.50 & 327,659 & 2.58 & 25,588 & 1.20 & 160,010 & 1.16 & 740,889 & 2.16 & 407,273 & 1.24 & 376,300 & 21.93 & $1,048,688$ \\
\hline July 11, 2013 & 3.19 & 353,547 & 2.50 & 29,962 & 1.22 & 133,501 & 1.25 & 545,641 & 2.16 & 625,739 & 1.26 & 723,132 & 22.16 & $1,203,728$ \\
\hline July 10, 2013 & 3.32 & 138,076 & 2.58 & 33,792 & 1.21 & 328,597 & 1.27 & 378,545 & 2.16 & 610,893 & 1.27 & 996,510 & 21.91 & 763,645 \\
\hline July 9, 2013 & 3.25 & 434,041 & 2.56 & 51,703 & 1.19 & 218,833 & 1.28 & 392,169 & 2.05 & 410,695 & 1.21 & 756,820 & 21.96 & $1,401,503$ \\
\hline July 8, 2013 & 2.96 & $1,172,607$ & 2.55 & 27,733 & 1.25 & 589,607 & 1.29 & 679,252 & 2.03 & 689,124 & 1.19 & 861,697 & 21.47 & $1,616,642$ \\
\hline July 5, 2013 & 3.41 & 636,458 & 2.58 & 49,093 & 1.21 & 219,154 & 1.27 & 603,376 & 2.13 & 407,795 & 1.16 & 375,657 & 20.71 & 661,592 \\
\hline July 3, 2013 & 5.64 & 95,111 & 2.63 & 51,767 & 1.19 & 183,809 & 1.31 & 424,142 & 2.09 & 276,427 & 1.19 & 173,281 & 20.68 & 372,978 \\
\hline July 2, 2013 & 6.65 & 75,893 & 2.70 & 97,396 & 1.19 & 441,544 & 1.28 & 836,341 & 2.05 & 632,956 & 1.16 & 447,973 & 20.67 & 969,173 \\
\hline July 1, 2013 & 7.33 & 22,576 & 2.60 & 37,562 & 1.14 & 589,475 & 1.33 & $1,006,478$ & 1.99 & 608,059 & 1.17 & 505,214 & 20.66 & 368,324 \\
\hline Jun. 28, 2013 & 7.25 & & 2.63 & & 1.10 & & 1.34 & & 1.79 & & 1.18 & & 20.55 & \\
\hline Dec. 31, 2012 & 13.25 & & 3.20 & & 1.39 & & 0.85 & & 2.56 & & 1.25 & & 19.72 & \\
\hline Dec. 30, 2011 & 28.50 & & 7.30 & & 1.82 & & 0.86 & & 3.06 & & 1.25 & & 18.05 & \\
\hline Mar. 12, 2011 & 114.75 & & 17.50 & & 3.20 & & 1.82 & & 3.92 & & 2.44 & & 32.62 & \\
\hline Mar. 11, 2011 & 129.00 & & 23.25 & & 3.95 & & 2.51 & & 4.85 & & 3.14 & & 37.38 & \\
\hline
\end{tabular}

Stock market data is from www.nasdaq.com and compared with finance.yahoo.com and www.google.com/finance to check for the accuracy of data.

This stock movement is very unusual. Why did the stock price change so dramatically? What happened to the corporation and the stock price? These questions are addressed based on given public information and an analysis of the drastic stock price changes in this case.

\section{POSSIBLE EXPLANATIONS FOR THE UNUSUAL PRICE CHANGES}

\section{Mean Reversion}

It is generally believed that an asset market value fluctuates around its fundamental values, but some studies also prove that market valuations can diverge from fundamental values. For example, Summers (1986) demonstrates that market valuations can differ substantially and persistently from the rational expectation of the present value of cash flows. DeBondt and Thaler (1985) show that portfolios of losers experience exceptionally large January returns as late as five years after portfolio formulation and imply that the stock market tends to overreact. Fama and French (1988) and Poterba and Summers (1988), however, provide direct empirical evidence that mean reversion occurs in U.S. stock prices, which refers to a tendency of asset prices to return to a fundamental value path. Could USU stock price increase be a result of mean reversion? Could USU have declined too much in the last two years causing the stock to be undervalued and ready for a value correction? 
On March 2011, Japan was struck by the Great East Japan Earthquake which triggered powerful tsunami waves, causing a severe nuclear accident at the Fukushima Daiichi Nuclear Power Plant. Many nuclear generators were taken down and at least three nuclear reactors suffered explosions. A nuclear emergency was declared in Japan and 140,000 residents within $20 \mathrm{~km}$ of the plant were evacuated. As a consequence, the Japanese are increasingly anti-nuclear and distrust government information on radiation. An energy white paper, approved by the Japanese Cabinet in October 2011, calls for a reduction of the nation's reliance on nuclear power. Japan's nuclear plants were gradually shut down or their operation was suspended for safety inspections, leaving Japan completely without nuclear-produced electrical power on May 2012. In addition to Japan, many other countries either cut or closed their nuclear power plants, as they suspended the construction of their nuclear power plants. For example, Germany permanently shut down eight of its reactors and pledged to close the rest by 2022 .

The Fukushima nuclear disaster had a substantial impact on the nuclear industry. On the very next trading day after the tsunami, all U.S. publicly-traded uranium stocks dropped badly ranging from $11.0 \%$ to $27.5 \%$, as shown in Table 1. They have been consistently declining since then. From March 11, 2011 to June 28, 2013 - the last day of trading in June 2013, uranium stocks decreased 94.4\%, 88.7\%, 72.2\%, 46.6\%, 63.1\%, 62.4\%, and 45.0\% for USU, URRE, URZ, URG, UEC, DNN, and CCJ, respectively, which is because Japan and other countries shut down nuclear fleets leading to a near-term oversupply condition in the uranium market. Since the event, uranium spot market prices have fallen over $50 \%$ - from $\$ 73.00$ per pound to $\$ 34.50$ per pound at the end of June 2013 .

As shown in Table 2, USEC Inc. had a steep decline in uranium sales - from $\$ 236$ million in 2010 to $\$ 132$ million in 2011 and a mere $\$ 26$ million in 2012. Its operating and net incomes deteriorated very rapidly, too. In the fiscal year 2010, it had positive, though small, operating income and net income. The company had \$247 million of operating loss and an overall loss of $\$ 491.1$ million in 2011. The operating loss accelerated to $\$ 1,140$ million and the net loss amounted to $\$ 1,188$ million in 2012. Its stock price collapse reflected the deterioration of financial performance. Comparing the first two quarters in 2013 with the same quarters in 2012, the firm's business is not changing for good. From the first quarter in 2012 to the first quarter in 2013, its revenue declined from $\$ 562$ million to $\$ 320$ million, its operating loss rose from $\$ 14$ million to $\$ 48$ million, and net loss increased from $\$ 23$ million to $\$ 58.4$ million. For the latest quarter, the financial numbers are not getting better. The latest information has more influence on the stock price than the older information. Compared to the second quarter in 2012, its revenue continued to decline from $\$ 365$ million to $\$ 285$ million in the second quarter in 2013, operating loss increased from $\$ 88$ million to $\$ 105$ million, and net loss slightly improved from $\$ 90$ million to $\$ 71$ million. To summarize, the rapid decrease of the stock price in the last two years simply reflected the company's business decline and the horrendous deterioration of financial numbers. In the latest quarters, there were no obvious signs showing any improvement in the business and accounting numbers.

Table 2: Financial Highlight For USEC Inc. (in million dollars)

\begin{tabular}{|l|c|c|c|c|c|c|c|c|c|}
\hline & Revenue & $\begin{array}{c}\text { Uranium } \\
\text { Sales }\end{array}$ & $\begin{array}{c}\text { Gross } \\
\text { Profit }\end{array}$ & $\begin{array}{c}\text { Operating } \\
\text { Income }\end{array}$ & $\begin{array}{c}\text { Net } \\
\text { Income }\end{array}$ & $\begin{array}{c}\text { Free Cash } \\
\text { Flow }\end{array}$ & Cash & $\begin{array}{c}\text { Interest- } \\
\text { Bearing Debt }\end{array}$ & $\begin{array}{c}\text { Common } \\
\text { Equity }\end{array}$ \\
\hline FY 2010 & 2,035 & 236 & 158 & 34 & 7.5 & 51 & 151 & 660 & 1,314 \\
FY 2011 & 1,672 & 132 & 84 & $(247)$ & $(491.1)$ & $(441)$ & 38 & 615 & 752 \\
FY 2012 & 1,918 & 26 & 138 & $(1,140)$ & $(1,188.3)$ & $(1,151)$ & 293 & 613 & $(473)$ \\
1Q'2012 & 562 & - & 37 & $(14)$ & $(23.0)$ & $(13)$ & 72 & 615 & 729 \\
2Q'2012 & 365 & 4 & 12 & $(88)$ & $(98.9)$ & $(90)$ & 229 & 615 & 643 \\
3Q'2012 & 571 & - & 38 & $(20)$ & $(28.6)$ & $(21)$ & 303 & 615 & 652 \\
4Q'2012 & 459 & 22 & 55 & $(1,018)$ & $(1,038)$ & $(1,028)$ & 293 & 613 & $(473)$ \\
1Q'2013 & 320 & 28 & 13 & $(48)$ & $(58.4)$ & $(49)$ & 87 & 530 & $(470)$ \\
2Q'2013 & 285 & 14 & $(47)$ & $(105)$ & $(77.9)$ & $(71)$ & 198 & 530 & $(419)$ \\
\hline
\end{tabular}

Accounting information has a direct impact on the stock price; however, other news can drive stock price as well. After checking all public uranium corporations' news releases and searching the LexisNexis database, no significant public information was found to show that USEC Inc. and the uranium industry were recovering or poised to rebound in July 2013. For example, no company announced any significant improvement in its business, no country decided to restart its nuclear power program, and a few mine companies announced deferral or cancellation of some of their large uranium projects as a result of the uranium price drop. This may potentially be good news because it will reduce the future supply of uranium and relieve the glut of uranium supply. 
From hindsight, it is not surprising to find no plausible reasons justifying the unusual performance of USEC Inc. stock in July 2013. USU did not stay at the high level and instead dropped back to pre-reverse-split level by early November 2013 and other uranium stocks remained depressed in the second half of 2013. Uranium spot market prices stayed in the low $\$ 30$ s.

Therefore, there is no compelling evidence indicating that the stock of USEC Inc., along with other uranium companies' stocks, was severely undervalued and ready for the huge increases within a period of one month. In addition, the literature shows that mean reversion, if it exists, is thought to be slow and can only be picked up over long horizons. For example, Balvers, Wu, and Gilliland (2000) found strong evidence of mean reversion with a half-life of three to three and one-half years. In addition, mean reversion cannot explain the initial sudden decline after the reverse stock split and then steep 10-times increase with little substantive information release and business development. Even if the stock were undervalued and the reverse stock split improves the market's perception of the stock and broadens the appeal of the stock to investors, it does not make much sense for the stock to initially plummet before rising purely based on the theory of mean reversion.

\section{Information-Based Manipulation}

Market manipulation has been an important issue since the Amsterdam Stock Exchange was founded at the beginning of the seventeenth century. According to former SEC Commissioner Laura Unger (2000), market manipulations are the most prevalent of three traditional types of securities fraud. ${ }^{2}$ Worldwide, security market regulating agencies have taken action to eradicate manipulation. In the United States, the Securities Exchange Act of 1934 was established to eliminate manipulation.

Allen and Gale (1992) classify manipulation into three categories - action-based, information-based, and trade-based manipulation. Action-based manipulation ${ }^{3}$ is based on actions that change the actual or perceived value of the assets. The Act attempted to eradicate action-based manipulation by, among other things, making it illegal for directors and officers to sell short the securities of their own firm. It is relatively easier to detect and outlaw this type of manipulation.

Information-based manipulation is based on releasing or spreading false information or disseminating false rumors. There are a number of provisions of the Act designed to eliminate information-based manipulation. Firms were required to disclose information to the public regularly and fairly to make it difficult to spread rumors. The Act also made it illegal for anybody to attempt to raise or depress stock prices by making statements which they knew to be false.

However, in modern financial markets, manipulations are often taken in hidden ways that cannot be easily eradicated and outlawed. Sabherwal, Sarkar, and Zhang (2011) find that an online message board can be used to manipulate the price of a vulnerable stock with small market capitalization, weak financials, and low institutional holdings. These stocks are more vulnerable to stock manipulation because of their thin float and lack of broad ownership (Aggarwal \& Wu, 2006).

The online "pump and dump" via message board postings is best exemplified by a case related to NEI Webworld, Inc. as mentioned by Unger (2000). The company's stock closed on a Friday at 13 cents. Over the weekend, two UCLA students used university library computers to send hundreds of false message board postings over the Internet stating that the company was to be acquired by another company. The stock rose to $\$ 15$ on Monday and the two sold their stocks making $\$ 364,000$ in trading profits.

\footnotetext{
${ }^{2}$ The other two are offering frauds characterized by promises of unrealistic returns with little or no disclosure of risks and, in many cases, involving the outright misappropriation of customer funds, and illegal touting characterized by unlawfully publicizing a security for which touts are being paid unless they disclose the nature, amount, and source of the compensation.

${ }^{3}$ A good example of action-based manipulation is related to American Steel and Wire Company. In 1901 the managers of the company shorted the firm's stock and then closed its steel mills. When the closure was announced, the stock price fell from around $\$ 60$ to around $\$ 40$ per share. The managers then covered their short positions and reopened the mills, at which point the stock price rose to its previous level.
} 
Following Sabherwal, Sarkar, and Zhang (2011), an investigation of TheLion.com, a chatroom-like message board aggregator, was conducted, which revealed that the majority of messages on USU were from Yahoo! Finance during July 2013; then, the focus was placed on Yahoo! Finance. After examining all messages on Yahoo! Finance, there are two observations:

1. On the day with large stock price increases and trading volume, such as July 22, July 26, July 29, and the following trading days, there was abnormally high posting activity. This is consistent with the findings of Tumarkin and Whitelaw (2001), Tumarkin (2002), and Antweiler and Frank (2004). They found that changes in online investor opinion are correlated with contemporaneous returns and trading volume but do not apparently predict returns.

2. No substantive messages were found on USEC Inc. Most online messages either reiterate their strong sentiment, bash opponents, or recommend other stocks. Most importantly, no messages similar to the two UCLA students' postings as mentioned above were found.

Liu, Smith, and Syed (1990) examine the impact of the "Heard-on-the-Street" column of The Wall Street Journal on common stock prices. They find that the HOTS column appears to have an impact on stock prices on the publication day and a small, but statistically significant, impact on two days preceding the publication. The HOTS column is published online. An investigation finds that USEC Inc. was never recommended on the HOTS column.

In addition, no commentary articles were found to promote USEC Inc. stock after searching Zacks.com and Motley Fool, which are popular stock recommending websites. Nevertheless, two articles by two different authors from Seeking Alpha (SA) were published on Sunday afternoon, July 7, 2013, before the stock market opened on Monday morning, July 8, 2013. One shows a positive tone and another displays a pessimistic view. Both could have impacted the stock price when the market opened on July 8. In fact, the stock decreased $13.2 \%$ on heavy volume on that day. It is not clear how these two articles affect the stock price.

Overall, no compelling evidence was found to support information-based manipulation. The two SA articles may affect the stock price, but it is difficult to argue that they caused the 10-times stock price rise in the following three weeks.

\section{Trade-Based Manipulation}

The Security Act of 1934 has, by and large, been fairly successful in eradicating action-based and information-based manipulation. It is much more difficult to eradicate trade-based manipulation. Trade-based manipulation occurs when a manipulator attempts to influence stock price simply by buying and then selling without taking any publicly observable actions to change the value of the firm or releasing false information to manipulate the price. A number of models (Allen \& Gale, 1992; Aggarwal \& Wu, 2006; Jarrow, 1992; Takayama, 2010; Mei, Wu, \& Zhou, 2004; Chatterjea \& Jarrow, 1998) demonstrate that trade-based manipulation is possible in the security market. For example, Allen and Gale (1992) show that an uninformed speculator can make a profit by simply buying and selling a security when investors are uncertain whether he has good information about the firm's prospects (i.e., the stock is undervalued) or he intends to manipulate the price. Jarrow (1992) develops a model to analyze trade-based manipulation in a stochastic framework. In his model, a large trader (speculator) trades in a stock and money market account. He demonstrates the existence of market manipulating trading strategies like a market corner and short squeeze or trend creation and trading against it. Mei, Wu, and Zhou (2004) consider three types of traders - behavior-driven investors who are less willing to sell losers than to sell winners, arbitrageurs, and manipulators. They show that, due to the investors' behavioral biases and the limit of arbitrage, the manipulator can profit from a "pump-and-dump" trading strategy by just trading the speculative asset. They provide a purely tradebased explanation on why asset prices can fluctuate without significant news on earning or other fundamental variables.

There are also many examples of traded-based manipulation. Aggarwal and Wu (2006) analyzed 142 stock market manipulation cases pursued by Security Exchange and Commission (SEC) from January 1990 to October 2001. The majority of manipulation cases occur in OTC markets, such as the OTC Bulletin Board and the Pink Sheets, and the regional exchanges where there are much lower disclosure requirements for their listed firms. Most 
manipulation cases involve the inflation of stock prices, whereas less than $1 \%$ of cases involve the deflation of stock prices. Manipulators often try to create an artificially high price through wash trades and the use of nominee accounts. Over half of all cases involve the spread of rumors. Historically, manipulators have colluded with newspaper columnists and stock promoters to spread false information. With the advent of the Internet, chat rooms and message boards have become popular means to distribute false information. From January 2000 to October 2001, about $39 \%$ of all manipulation cases involved the use of the Internet to spread rumors. During the sample period, average daily return, liquidity, and volatility were significantly higher for manipulated stocks than the benchmark. This is consistent with most models of trade-based manipulation such as Allen and Gale (1992).

Using unique trade level data containing all daily trades of each broker in every stock trading during a two and a half year period on the Karachi Stock Exchange in Pakistan, Khwaja and Mian (2005) found compelling evidence for trade-based "pump and dump" price manipulation schemes and revealed how investors manipulate the stock prices. When prices are low, colluding brokers trade among themselves (i.e., wash sale) to artificially raise prices and attract information-seeking traders. Once prices have risen, the former exit, leaving the latter to suffer the ensuing price fall. They show that brokers earn annual rates of return that are 50-90 percentage points higher than those earned by outside investors.

In modern financial markets, high frequency trading (HFT) makes manipulation less difficult (Angel \& McCabe, 2013). HFT refers to the use of computers to trade very quickly and at high speed. HFT makes large block wash sales easier to implement. Using a wash sale, a manipulator can put in simultaneous buy-and-sell orders through different accounts to make it look like there is trading interest in the stock. The manipulator does this at higher prices to push the stock price and also to make it appear that the market is more liquid than it really is. Information seekers will observe (artificial) volume and price increases and incorrectly infer that there is news behind the volume. Some will decide to follow.

Trade-based manipulation can explain the unusual movement of USEC Inc. stock for the following reasons:

1. Manipulation can push the stock price up and drive it down, particularly for small-cap stocks due to its low selling and buying interest and short sale constraints. USU lost $60 \%$ value during four trading days after the reverse stock split and then increased by almost 10 times during the subsequent sixteen trading days. USU is small with only 4.7 million tradable shares and it is also a thinly-traded stock with average daily volume of 32,846 shares in the 52 weeks prior to July 2013.

2. According to Aggarwal and $\mathrm{Wu}$ (2006) and Khwaja and Mian (2005), liquidity and volatility turn significantly higher as manipulators move the stock price through wash sales. The average daily trading volume of USU was about 1.28 million shares in July 2013 compared to 18,097 in June. The mean turnover was $24.13 \%$ in July, while it was only $0.37 \%$ in June and $14.96 \%$ in August, as shown in Table 3. The standard deviation of daily returns increased from $5.54 \%$ in June to $28.93 \%$ in July and declined to $8.71 \%$ in August. These numbers are consistent with the findings of Aggarwal and Wu (2006) and Khwaja and Mian (2005). They found that average turnover and volatility are higher during the manipulation period than that during the pre-manipulation and post-manipulation periods.

3. During the post-manipulation period, the stock price will slowly retreat as manipulators quietly pull out of the market. Consistent with the manipulation theory, USU gradually decreased to its pre-reverse-split level after three months. Given the fact that the stock price declined, it can be inferred that the stock price did not reflect its real value in July and was inflated. 
Table 3: Mean Return, Volatility and Turnover for USU and Its Competitors

\begin{tabular}{|c|c|c|c|c|c|}
\hline & & Aug-13 & Jul-13 & Jun-13 & Prior 52-week \\
\hline \multirow{3}{*}{ USU } & Mean Return & $-1.91 \%$ & $10.69 \%$ & $-0.95 \%$ & $-0.33 \%$ \\
\hline & Std. Dev. & $8.71 \%$ & $28.93 \%$ & $5.54 \%$ & $5.61 \%$ \\
\hline & Mean Turnover & $14.96 \%$ & $24.13 \%$ & $0.37 \%$ & $0.67 \%$ \\
\hline \multirow{3}{*}{ URRE } & Mean Return & $-1.91 \%$ & $4.38 \%$ & $-0.54 \%$ & $-0.17 \%$ \\
\hline & Std. Dev. & $5.90 \%$ & $11.44 \%$ & $3.67 \%$ & $6.26 \%$ \\
\hline & Mean Turnover & $2.93 \%$ & $4.27 \%$ & $0.41 \%$ & $0.63 \%$ \\
\hline \multirow{3}{*}{ URZ } & Mean Return & $-1.51 \%$ & $1.76 \%$ & $-0.59 \%$ & $-0.03 \%$ \\
\hline & Std. Dev. & $3.73 \%$ & $6.11 \%$ & $2.57 \%$ & $3.70 \%$ \\
\hline & Mean Turnover & $0.63 \%$ & $0.84 \%$ & $0.71 \%$ & $0.44 \%$ \\
\hline \multirow{3}{*}{ URG } & Mean Return & $-0.94 \%$ & $0.02 \%$ & $1.09 \%$ & $0.30 \%$ \\
\hline & Std. Dev. & $3.30 \%$ & $4.79 \%$ & $4.38 \%$ & $3.38 \%$ \\
\hline & Mean Turnover & $0.39 \%$ & $0.51 \%$ & $0.94 \%$ & $0.26 \%$ \\
\hline \multirow{3}{*}{ UEC } & Mean Return & $-0.20 \%$ & $1.26 \%$ & $-0.26 \%$ & $0.01 \%$ \\
\hline & Std. Dev. & $3.10 \%$ & $3.86 \%$ & $4.29 \%$ & $3.72 \%$ \\
\hline & Mean Turnover & $0.56 \%$ & $0.82 \%$ & $0.80 \%$ & $0.67 \%$ \\
\hline \multirow{3}{*}{ DNN } & Mean Return & $-0.49 \%$ & $0.64 \%$ & $-0.37 \%$ & $0.01 \%$ \\
\hline & Std. Dev. & $1.83 \%$ & $2.92 \%$ & $1.85 \%$ & $3.06 \%$ \\
\hline & Mean Turnover & $0.13 \%$ & $0.23 \%$ & $0.16 \%$ & $0.15 \%$ \\
\hline \multirow{3}{*}{$\mathrm{CCJ}$} & Mean Return & $-0.32 \%$ & $0.00 \%$ & $-0.22 \%$ & $-0.01 \%$ \\
\hline & Std. Dev. & $1.20 \%$ & $1.98 \%$ & $1.44 \%$ & $1.77 \%$ \\
\hline & Mean Turnover & $0.24 \%$ & $0.32 \%$ & $0.32 \%$ & $0.42 \%$ \\
\hline
\end{tabular}

Even though the above reasons are in line with the manipulation explanation, one cannot jump to the conclusion that the unusual stock movement of USU in July 2013 is due to trade-based manipulation without direct evidence. This case shows the characteristics of manipulation. However, these characteristics may, at most, be the necessary condition of manipulation. They are not sufficient to draw the conclusion.

\section{Speculative Bubble}

A growing number of studies (Miller, 1977; Harrison \& Kreps, 1978; Jarrow, 1981; Chen, Hong, \& Stein, 2002; Scheinkman \& Xiong, 2003; Ofek \& Richardson, 2003; Hong, Scheinkman, \& Xiong, 2006) investigate asset prices based on the combined effects of heterogeneous beliefs (i.e., divergence of opinions) and short-sale constraints, and show that securities can be overpriced. For example, Harrison and Kreps (1978) show that asset prices may exceed their fundamental values when agents agree to disagree and short selling is not possible. In their model, agents disagree about the probability distributions of dividend streams. Scheinkman and Xiong (2003) introduce a continuous-time equilibrium model in which overconfidence generates disagreements among agents regarding asset fundamentals. With short-sale constraints, a speculative bubble can arise. The magnitude of the bubble depends on such factors as the degree of overconfidence, trading costs, etc.

Heterogeneous beliefs may come in many ways; overconfidence is one of them. An extensive study from psychology finds that people exhibit overconfidence in some circumstances, especially for challenging judgment tasks (Alpert \& Raiffa, 1982). DeBondt and Thaler (1995) state that "perhaps the most robust finding in psychology of judgment is that people are overconfident." Experts can be more prone to overconfidence than non-experts when predictability is low and evidence is ambiguous (Griffin \& Tversky, 1992). Overconfidence has been analyzed numerous times in the finance literature in studies related to investors' behaviors (DeBont \& Thaler, 1985; Oden, 1998; Daniel, Hirshleifer, \& Subrahmanyam, 1998). In these papers, overconfidence is referred to as an overestimation of the precision of one's information. This research finds that investors are often overconfident.

Many studies (Ofek \& Richardson, 2003; Jones \& Lamont; 2002; Scheinkman \& Xiong, 2003) document short sale-constraints, including various costs and risks of shorting, as well as legal and institutional restrictions. First, to be able to sell a stock short, one must borrow it and, because borrowing shares is not done in a centralized market, finding shares sometimes can be difficult or impossible, particularly for stocks that are small, have low institutional ownership, or are in high demand for borrowing. Second, lenders receive a fee in the form of interest 
payments generated by the short-sale proceeds minus any interest rebate that the lenders return to the borrowers. Ofek and Richardson (2003) find that the rebate rate is significantly lower for inflated Internet stocks than other stocks indicating higher trading costs for overpriced stocks. Third, a short seller may be forced to close a short position if the lender recalls the stock loaned to the short seller. This possibility leads to recall risk - one of many risks that short sellers are exposed to. In addition to the restrictions in the stock lending market mentioned above, there are other legal and institutional constraints. For example, most mutual funds are long only. In times of crises or following major price declines, short sellers are often blamed, and short selling may even be banned.

When investors have heterogeneous beliefs due to overconfidence or other reasons and there are short-sale constraints, the price of an asset can exceed its fundamental value for two reasons. First, when investors' beliefs are sufficiently different, price only reflects the beliefs of the optimistic group as short-sale constraints can prevent negative information or opinion from being expressed in stock prices (Miller, 1977). In other words, short-sales restrictions force the pessimistic investors out of the market, leaving only optimistic investors and thus inflated asset price levels. Second, investors pay prices that exceed their own valuation of future dividends as they anticipate finding a buyer willing to pay even more in the future.

Scheinkman and Xiong (2003) show that bubbles are accompanied by large trading volume and high price volatility. Ofek and Richardson (2003) reveal that, during the period of the Internet Bubble, when Internet stock prices rise, trading volume increases, and institutional trading decreases. Their findings are consistent with Chen, Hong, and Stein (2002) who argue that overvalued firms will have lower breadth of institutional ownership. Hong, Scheinkman, and Xiong (2006) model the relationship between asset float (tradable shares) and speculative bubbles and analyze the Internet Bubble during the late 1990's. They found that the bubble's size depends on float.

A pro-nuclear Prime Minister Shinzo Abe was elected on Sunday, July 21, 2013. As shown in Table 1, on the following trading day, USEC Inc. stock almost doubled - from $\$ 6.05$ to $\$ 11.98$ - on huge volume, while its uranium competitors' stock also increased, but to a lesser degree - by $23.0 \%, 21.4 \%, 14.5 \%, 12.3 \%, 5.6 \%$, and $3.5 \%$ for URRE, URZ, URG, UEC, DNN, and CCJ, respectively, on relatively large volume. Since Japan's Fukushima Daiichi accident, occurring as a result of the March 11, 2011 earthquake and subsequent tsunami, Japan's nuclear fleet remains largely offline and is contributing to a near-term oversupply condition in the uranium market. After Abe was elected, uranium investors speculated that the new pro-nuclear Prime Minister would make efforts to reopen Japan's nuclear power plants which would relieve the oversupply condition in the uranium market leading to higher uranium prices and, as a result, improve the financial situation of uranium companies. From hindsight, investors appear to have been overly confident with their judgments as the Japanese government did not reopen any nuclear power plants by the end of 2013. Uranium stocks all went back to the pre-election level after about three months.

In the subsequent four days, USU skyrocketed to $\$ 19.21$ on large trading volume from the closing price of $\$ 11.98$ on July 22 , tripling after the Japanese election while its public competitors mostly remained unchanged. During this period, there was no firm-specific information released by USEC Inc. that could account for the huge stock price increase. The potential improvement of Japanese uranium market will benefit USEC Inc. However, there seems to be no reason to believe that USEC Inc. will benefit much more than its competitors. As shown in Table 4, only about 10 percent of its revenue comes from the Japanese market. A speculative bubble may explain the 3-times stock price surge after Abe was elected. Investors are overly optimistic with the precision of their information and their judgment. As they traded on this information, the stock price increased, as did trading volume. On the other hand, more realistic investors will be left out of the market due to short-sale constraints. The stock price increase attracts information seekers who thought there might be some positive news behind the stock price rise. As they entered the market, the stock price was pushed higher. A speculative bubble was created similar to the Internet Bubble. 
Table 4: Revenue Attributed to Domestic and Foreign Customers (in million dollar)

\begin{tabular}{|l|c|c|c|c|c|c|}
\hline \multirow{2}{*}{} & \multicolumn{2}{|c|}{$\mathbf{2 0 1 2}$} & \multicolumn{2}{c|}{$\mathbf{2 0 1 1}$} & \multicolumn{2}{c|}{$\mathbf{2 0 1 0}$} \\
\cline { 2 - 7 } & \multicolumn{2}{|c|}{ Year Ended December 31, } \\
\hline United States & $1,584.2$ & $82.6 \%$ & $1,322.7$ & $79.1 \%$ & $1,487.5$ & $73.1 \%$ \\
Japan & 183.7 & $9.6 \%$ & 200.0 & $12.0 \%$ & 199.7 & $9.8 \%$ \\
Others & 150.2 & $7.8 \%$ & 149.1 & $8.9 \%$ & 348.2 & $17.1 \%$ \\
Total revenue & $1,918.1$ & $100.0 \%$ & $1,671.8$ & $100.0 \%$ & $2,035.4$ & $100.0 \%$ \\
\hline
\end{tabular}

\section{SUMMARY AND CONCLUSIONS}

It seems to be reasonable to rule out mean reversion and information-based manipulation as explanations of the astounding performance of USEC Inc. stock. No compelling evidence can be found to show that USEC's business was improving in July 2013 leading to its value correction. No false information can be found in popular stock message boards to support information-based manipulation. USU was not mentioned in major stock promotion column or websites either.

Trade-based manipulation and speculative bubbles provide better explanations. Putting USEC Inc. aside and focusing on its publicly traded competitors, it seems that the uranium sector experienced some speculation after the election of pro-nuclear Prime Minister Shinzo Abe on July 21, 2013. From July 21 to July 29, when USU reached the highest price, its small, speculative development-stage competitors - URRE, URZ, URG, and UEC increased by $104.6 \%, 31.6 \%, 12.0 \%$, and $13.7 \%$, respectively, while its larger competitor - DNN - rose by only $4.8 \%$ and the industry flagship - CCJ - actually declined by 3.5\%. After Abe was elected, some investors speculated that uranium price would increase based on the hope that Prime Minister Abe would reopen Japanese nuclear power plants. According to Scheinkman and Xiong (2003), some investors' excessive optimism and short-sale constraints, particularly limited number of shares for short due to low institutional ownership of small corporations' stock, could create a bubble. Due to their significantly larger size and, more importantly, its higher institutional ownership, the short-sale constraints were less severe for DNN and particularly CCJ. Their stock did not see as big of an increase as other smaller development-stage competitors. The fact that these stocks declined to pre-election levels within one to three months proves that stock prices were indeed inflated. During the same period, USU was up by $380.0 \%$. The Japanese market only accounts for approximately $10 \%$ of USEC Inc. revenue. Thus, there are more reasons to believe that USU was engaged in a speculative bubble if other uranium stock price increases are due to speculation.

There is no reason not to suspect trade-based stock manipulation, even though there is no direct evidence to prove it. First, on July 22 alone - the day after Prime Minister Abe was elected - USU rose by $98.0 \%$ compared to $23.0 \%, 21.4 \%, 14.5 \%, 12.3 \%, 5.6 \%$, and $3.5 \%$ for URRE, URZ, URG, UEC, DNN, and CCJ, respectively, despite the fact that USEC Inc. generates only about $10 \%$ of its revenue from Japan and possible uranium price improvement will benefit all uranium suppliers. Second, on July 29 when the company updated its American centrifuge research, development, and demonstration program and indicated that the program is on budget and on schedule, USU surged from $\$ 19.21$ on the previous trading day (July 26) to $\$ 29.02$ on large volume. It then retreated back to $\$ 19.48$ on July 30 . It seems hard to believe that investors' optimism stayed for just one day; it would make more sense if someone manipulated the stock price on the seemingly good news. Third, the characteristics of speculative bubble and market manipulation are the same. While the stock price surged due to either reason, the trading volume, price volatility, and turnover all increased. This makes it difficult to distinguish the speculative bubble and market manipulation. There may be a possibility that both occurred at the same time. In the 1920's, the stock market was roaring due to investors' optimism. On the other hand, the Senate Committee on Banking and Currency uncovered extensive evidence of other types of manipulation, such as a trading pool (Allen \& Gale, 1992). A group of investors combined first to buy a stock, then to spread favorable rumors about the firm, and, finally, to sell out at a profit.

While anecdotes abound, the lack of suitable data has made it difficult to eradicate the stock market manipulation. The speculative bubble and trade-based manipulation are two possible explanations of the seemingly "pump-and-dump" scheme in the case of USEC Inc. Finding out for certain whether the speculative bubble, stock manipulation, or other reasons led to the unusual stock price increase of USEC Inc. in July 2013 will likely take a formal SEC Division of Enforcement investigation. 


\section{AUTHOR INFORMATION}

Xiaofeng Zhao, Ph.D., CFA, David Rankin Professor of Finance, Southern Arkansas University, Department of Accounting, Finance and Economics, P.O. Box 9309, Magnolia, AR 71754. E-mail: 1xzhao@ saumag.edu

\section{REFERENCES}

1. Aggarwal, R. K., \& Wu, G. (2006). Stock market manipulations. Journal of Business, 79(4), 1915-1953.

2. Allen, F., \& Gale, D. (1992). Stock-price manipulation. The Review of Financial Studies, 5(3), 503-529.

3. Alpert, M., \& Raiffa, H. (1982). A progress report on the training of probability assessors. In D. Kahneman, P. Slovic, \& A. Tversky (eds.), Judgement under uncertainty: Heuristics and biases. Cambridge: Cambridge University Press.

4. Angel, J., \& McCabe, D. (2013). Fairness in financial markets: The case of high frequency trading. Journal of Business Ethics, 112(4), 585-595.

5. Antweiler, W., \& Frank, M. (2004). Is all that talk just noise? The information content of internet stock message boards. Journal of Finance, 59(3), 1259-1295.

6. Balvers, R., Wu, Y., \& Gilliland, E. (2000). Mean reversion across national stock markets and parametric contrarian investment strategies. Journal of Finance, 55(2), 745-772.

7. Chatterjea, A., \& Jarrow, R. A. (1998). Market manipulation, price bubbles, and a model of the U.S. treasury securities auction market. Journal of Financial and Quantitative Analysis, 33(2), 255-289.

8. Chen, J., Hong, H., \& Stein, J. (2002). Breadth of ownership and stock returns. Journal of Financial Economics, 66(2), 171-205.

9. Daniel, K., Hirshleifer, D., \& Subrahmanyam, A. (1998). Investor psychology and security market underand overreaction. Journal of Finance, 53(6), 1839-1885

10. Daniel, K., Hirshleifer, D., \& Subrahmanyam, A. (2001). Overconfidence, arbitrage, and asset pricing. Journal of Finance, 56(3), 921-965.

11. DeBondt, W., \& Thaler, R. (1985). Does the stock market overreact? Journal of Finance, 40(3), 793-805.

12. DeBondt, W., \& Thaler, R. (1995). Financial decision-making in markets and firms: A behavioral perspective. In R. A. Jarrow, V. Maksimovic, \& W. T. Ziemba (eds.), Finance, handbooks in operations research and management science. North Holland, Amsterdam.

13. Fama, E., \& French, K. (1988). Permanent and temporary components of stock prices. Journal of Political Economy, 96(2), 246-273.

14. Griffin, D., \& Tversky, A. (1992). The weighing of evidence and the determinants of overconfidence. Cognitive Psychology, 24, 411-435.

15. Harrison, M., \& Kreps, D. (1978). Speculative investor behavior in a stock market with heterogeneous expectations. Quarterly Journal of Economics, 92(2), 323-336.

16. Jarrow, R. (1981). Heterogeneous expectations, restrictions on short sales, and equilibrium asset price. Journal of Finance, 35(5), 1105-1113.

17. Jarrow, R. A. (1992). Market manipulation, bubbles, corners, and short squeeze. Journal of Financial and Quantitative Analysis, 27(3), 311-336.

18. Jones, C., \& Lamont, O. (2002). Short-sale constraints and stock returns. Journal of Financial Economics, 66(2), 207-239.

19. Khwaja, A. I., \& Mian, A. (2005). Unchecked intermediaries: Price manipulation in an emerging stock market. Journal of Financial Economics, 78(1), 203-241.

20. Liu, P., Smith, S., \& Syed, A. (1990). Stock price reactions to the Wall Street Journal's securities recommendations. Journal of Financial and Quantitative Analysis, 25(3), 399-410.

21. Mei, J., Wu, G., \& Zhou, C. (2004). Behavior based manipulation: Theory and prosecution evidence. (Working Paper). New York University

22. Miller, E. (1977). Risk, uncertainty and divergence of opinion. Journal of Finance, 32(4), 1151-1168.

23. Odean, T. (1998). Volume, volatility, price, and profit when all traders are above average. Journal of Finance, 53(6), 1887-1934.

24. Ofek, E., \& Richardson, M. (2003). DotCome mania: The rise and fall of internet stock prices. Journal of Finance, 58(3), 1113-1137. 
25. Poterba, J., \& Summers, L. (1988). Mean reversion in stock prices: Evidence and implications. Journal of Financial Economics, 22(1), 27-59.

26. Sabherwal, S., Sarkar, S. K., \& Zhang, Y. (2011). Do internet stock message boards influence trading? Evidence from heavily discussed stocks with no fundamental news. Journal of Business Finance \& Accounting, 38(9 \& 10), 1209-1237.

27. Scheinkman, J., \& Xiong, W. (2003). Overconfidence and speculative bubbles. Journal of Political Economy, 111(6), 1183-1219.

28. Summers, L. (1986). Does the stock market rationally reflect fundamental values? Journal of Finance, 41(3), 591-601.

29. Takayama, S. (2010). A dynamic strategy of the informed trader with market manipulation. Annuals of Finance, 6(2), 287-294.

30. Tumarkin, R., \& Whitelaw, R. (2001). News or noise? Internet postings and stock prices. Financial Analyst Journal, 57(3), 41-51.

31. Tumarkin, R. (2002). Internet message board activity and market efficiency: A case study of the internet service sector using RagingBull.com. Financial Markets, Institutions and Instruments, 11(4), 313-335.

32. Unger, L. S. (May 17, 2000). Speech: Empowering investors in an electronic age. IOSCO Annual Conference, Sydney, Australia 